\title{
Effects of a selective mu opioid receptor agonist and naloxone on the intake of sodium chloride solutions
}

\author{
Blake A. Gosnell and Mark J. Majchrzak \\ University of Michigan, Department of Psychiatry, University Hospital, 8D8806, Box 0116, Ann Arbor, MI 48109-0116, USA.
}

\begin{abstract}
Endogenous opioid peptides are thought to play a role in mediating the palatability or rewarding aspects of sweet tastes. There is also evidence, however, which suggests that opioids may influence the preference for the taste of salt as well. In the present studies, we measured the effects of central administration of naloxone and the mu agonist $\left[\mathrm{D}-\mathrm{Ala}^{2}, \mathrm{MePhe}^{4}, \mathrm{Gly}-\mathrm{ol}^{5}\right]$ enkephalin (DAGO) on the ingestion of salt solutions. In non-deprived rats given a choice of water and $0.6 \%$ saline, ICV injections of DAGO ( 1 and $3 \mathrm{nmol}$ ) significantly increased the intake of $0.6 \%$ saline; baseline water intake was minimal and was unaffected by DAGO. When rats were given a choice between water and $1.7 \%$ saline, DAGO stimulated both water and saline intake. Because $1.7 \%$ saline is a hypertonic solution, the increase in water intake may have been secondary to saline intake. In rats on a deprivation schedule in which water and $0.6 \%$ saline were available for only $2-3 \mathrm{~h} / \mathrm{day}$, there was a tendency for DAGO to increase $0.6 \%$ saline intake and decrease water intake, though these effects were not significant. In rats given water and $1.7 \%$ saline, DAGO increased saline intake and had no effect on water intake. Naloxone was also tested in water-deprived rats. Naloxone (20 and $50 \mu \mathrm{g}$ ) significantly decreased $0.6 \%$ saline intake; baseline water intake was low $(3-5 \mathrm{ml})$ and was unaffected by naloxone. When rats were given a choice between water and $1.7 \%$ saline, naloxone $(50 \mu \mathrm{g})$ significantly reduced water intake, while intake of $1.7 \%$ saline was slightly increased. These results suggest a role for central $\mathrm{mu}$ opioid receptors in mediating the preference for salt solutions.
\end{abstract}

Key words: Opioids - Saline intake - Naloxone - Reward - Palatability - Taste preference - Drinking

A number of studies have implicated endogenous opioid systems in the mediation of the palatability or reward value of food (LeMagnen et al. 1980; Calcagnetti and Reid 1983; Cooper 1983; Siviy and Reid 1983; Reid 1985; Czirr and Reid 1986; Lynch 1986; Cooper et al. 1988). These studies have dealt primarily with the effects of opioid agonists and antagonists on the intake of sweet-tasting liquids, such as sucrose, glucose and saccharin solutions. However, a few studies indicate that opioids may also be involved in the preference or rewarding aspects of other, non-sweet tasting

Offprint requests to: B.A. Gosnell fluids, such as salt and alcohol solutions (Cooper and Gilbert 1984; Kuta et al. 1984; Bertino et al. 1988; Wild et al. 1988). Cooper and Gilbert (1984) found that when rats were given simultaneous access to water and a hypotonic saline solution, naloxone caused a selective reduction in the intake of the saline solution. In experiments in which rats were given only one liquid (water, saccharin or saline solution), naloxone abolished the initial increased consumption of saline (Cooper and Turkish 1983). Both naloxone and the opioid antagonist Mr2266 reduced saline intake at lower doses than those required to reduce water intake (Levine et al, 1982; Ukai et al. 1988). In mice, Kuta et al. (1984) reported that naloxone reduced the intake of a $1.5 \%$ saline solution induced by immobilization stress, food deprivation, or the injection of angiotensin II. These studies suggest the possibility that an interaction exists between endogenous opioid systems and the preference for salt solutions.

As might be predicted from the effect of antagonists, the $\mathrm{mu}$ agonist morphine was found to increase intake of or preference for salt solutions. Bertino et al. (1988) found that in $1 \mathrm{~h}$ drinking tests with water-deprived rats, systemic injections of morphine increased rats' preference for isotonic $(0.9 \%)$ saline. In mice, morphine increased preference for $3.0 \%$ saline over water; preferences for 0.75 and $1.5 \%$ saline were not affected (Kuta et al. 1984).

Much evidence suggests that the effects of opioid agonists and antagonists on food and water intake are centrally mediated (see Levine et al. 1985; Gosnell 1987). Therefore, in the experiments reported here we measured saline and water intake after central injections of naloxone and [D$\mathrm{Ala}^{2}, \mathrm{MePhe}^{4}, \mathrm{Gly}_{-\mathrm{ol}^{5}}$ ]enkephalin (DAGO), a selective agonist at mu opioid receptors (Handa et al. 1981). Because the direction of the effect of some opioid agonists depends on the deprivation status of the animals (Sanger and McCarthy 1980; Turkish and Cooper 1984), we tested DAGO in non-deprived as well as deprived rats. These studies were designed to determine whether the effects of selective agonists delivered directly into the brain are similar to those observed after systemic administration of morphine.

\section{Materials and methods}

Animals and surgery. Male Sprague-Dawley rats, obtained from Charles River Laboratories, Inc. (Wilmington, MA), were used in all experiments. At the time of surgery, body 
weights ranged from 243 to $304 \mathrm{~g}$. They were individually housed in stainless steel cages, and food and water were available ad libitum except as described below. Lights were on for $12 \mathrm{~h}$ daily (on at 0700 hours), and all experiments were carried out in the light period. Under sodium pentobarbital anesthesia $(40-50 \mathrm{mg} / \mathrm{kg})$, a 20 gauge cannula was implanted into the right lateral ventricle of each rat with techniques similar to those previously reported (Gosnell et al. 1987). With the incisor bar set at $3.3 \mathrm{~mm}$ below the interaural line, the cannula was placed $1.0 \mathrm{~mm}$ posterior and $1.5 \mathrm{~mm}$ lateral to bregma and $3.54 .5 \mathrm{~mm}$ below the skull surface. Cannula placement was verified behaviorally by the observation of a drinking response to an ICV injection of angiotensin II (AII, $100 \mathrm{ng}$ ). AII was injected prior to the start of training sessions and at the completion of drug testing, and only those rats which drank $5 \mathrm{ml}$ or more of water in the $30 \mathrm{~min}$ following injection were included in data analyses.

Salt training sessions. At least 2 days after surgery, rats were deprived of water overnight. The next day at 1300 hours, they were moved to novel individual test cages with no food or water. One hour after being placed in these cages, two $25 \mathrm{ml}$ graduated burets fitted with stainless steel sipper tubes were attached to the front of each cage. For approximately one-half of the rats, one buret contained water and the other, $0.6 \%$ sodium chloride solution (saline) $(\mathrm{w} / \mathrm{v})$; the remaining rats received water and $1.7 \%$ saline solution. They were allowed $2 \mathrm{~h}$ of access to these liquids, after which they were returned to their home cages. Water was not available in the home cages; food was available in the home cages but not the test cages. This procedure was repeated daily for 9 additional days. Each rat was given the same saline concentration throughout the entire experiment. Positions of the water and saline burets were reversed daily to prevent the formation of position preferences. To prevent rats from simply drinking indiscriminately from the first buret placed on the cage, a "forced sampling" technique was used (Calcagnetti and Reid 1983; Siviy and Reid 1983). First, one buret was placed on the cage. After the rat had taken a few licks at the spout, this buret was removed and the other buret was put in place. After a few licks at the second solution, the buret was removed, after which both burets were replaced simultaneously. This procedure was omitted if a rat did not immediately begin to drink.

Test procedures. After 10 training days on the deprivation schedule, the intakes of water and saline solutions were measured after ICV injections of the opioid antagonist naloxone hydrochloride (Sigma Chemical Co., St. Louis, $\mathrm{MO})$. On the 1st test day, rats in both saline concentration groups $(0.6$ or $1.7 \%)$ were given ICV injections of 0,20 or $50 \mu \mathrm{g}(0,55$ and $138 \mathrm{nmol})$ naloxone in a $5 \mu \mathrm{l}$ volume. Naloxone was dissolved in water (HPLC grade), which was also used as the control injection. Injections were made with a 24 gauge injector which extended $1.0 \mathrm{~mm}$ beyond the tip of the guide cannula. Injections were given $45 \mathrm{~min}$ after placement into the test cages, and burets were placed on the cages $15 \mathrm{~min}$ after injection. On test days, rats were given $3 \mathrm{~h}$ access to saline and water, after which they were returned to their home cages. Saline and water intakes were measured every hour, and burets were refilled as needed. The test procedure was repeated two additional times, such that every rat was tested with placebo and with both doses of naloxone. Test days were 2 days apart, and a normal $2 \mathrm{~h}$ training session was given on the intervening days (no injections). Injection orders for testing the three doses were counterbalanced, and every dose was tested in at least one rat on each of the three test days.

As mentioned above, data from a given rat were excluded if a drinking response to AII was not observed both before training and after drug trials. Because this verification procedure excluded more animals than expected, additional rats were tested with methods similar to those described above. One minor exception was that these rats were given 1 day of training with only salt solutions available before 10 days of training days with both fluids. Data from these rats were similar to those from the original experiment and were therefore pooled to bring the group size to $n=11$ for the $0.6 \%$ saline concentration and to $n=10$ for the $1.7 \%$ concentration.

Initially, cumulative intake data were analyzed at each measurement $(1,2$ and $3 \mathrm{~h})$ with a three-factor analysis of variance (ANOVA): dose ( 3 levels) $\times$ fluid (water versus saline) $\times$ concentration ( 2 levels). Because a significant concentration $\times$ fluid interaction was obtained in every case, subsequent two-factor ANOVAs (dose $\times$ fluid) were performed considering each concentration separately. For each fluid, Dunnett's test (two-tailed) was then used at each measurement to compare saline and water intake in each naloxone condition to the control (water injection) condition.

Experiment 2 was designed to test the effects on saline intake of $\left[\mathrm{D}-\mathrm{Ala}^{2}, \mathrm{MePhe}^{4}, \mathrm{Gly}-\mathrm{ol}^{5}\right]$ enkephalin (DAGO), a selective agonist at mu opioid receptors (Handa et al. 1981). A separate group of animals was cannulated and trained to drink saline in a manner similar to that described above, with two exceptions: rats were transferred to test cages at 0800 hours each day, and injections were given at the time of transferral to the test cages $(1 \mathrm{~h}$ before access to water and saline solutions). DAGO (Sigma Chemical Co., St. Louis, MO) was dissolved in $0.9 \%$ saline and was tested at doses of 0 (saline), 1 and $3 \mathrm{nmol}$. These doses were chosen because they are in or below the range of doses which stimulate food intake (Gosnell et al. 1986, 1987 and unpublished observations). The 1-h delay between injections and fluid access was imposed because in previous studies, we have found that DAGO in this dose range produces a cataleptic state which dissipates within an hour.

In experiment 3 , the effects of DAGO on water and saline intake were tested in non-deprived rats. These animals were cannulated and trained in a manner identical to that in experiment 2 , with the exception that water was returned to the home cages after the first training session, and was available throughout the remainder of the experiment (except during the 1st hour in the test cages each day). In the first training session, only salt solutions were presented; in ten additional daily sessions, both water and salt solutions were available. The purpose of the deprivation prior to the first training session was to force the rats to sample the novel saline solutions. As was the case for experiment 1 , the cannula verification procedure excluded more rats from the $1.7 \%$ saline group than expected. Therefore, additional rats were tested with similar procedures to bring the final group sizes to $n=9$ for the $0.6 \%$ saline group and to $n=8$ for the $1.7 \%$ saline group. In this experiment, it was known that baseline intakes of both water and saline would be minimal. Therefore, one-tailed tests (Dunnett's) 
were used to compare the drug conditions to the placebo condition.

\section{Results}

In deprived rats receiving water and $0.6 \%$ saline, naloxone decreased intake of the saline solution only (Fig. 1). At 1,2 and $3 \mathrm{~h}$, there were significant effects of dose $[F(2,20)=$ $9.08,5.05$ and 5.27] and fluid $[F(1,10)=55.83,88.57$ and 87.55 , all $\left.P^{\prime} s<0.05\right]$. The dose $\times$ fluid interaction was significant at 1 and $3 \mathrm{~h}[F(2,20)=6.10$ and $3.94, P<0.05]$ and approached significance at $2 \mathrm{~h}(P=0,064)$. Both doses $(20$ and $50 \mu \mathrm{g}$ ) decreased $1 \mathrm{~h}$ saline intake; intake remained depressed for the entire 3 -h period following the $50 \mu \mathrm{g}$ dose. Mean water intake was low $(3.7-4.9 \mathrm{ml})$ and was not affected by naloxone. Saline preference (saline intake expressed as a percentage of total fluid intake) was not signifi- cantly affected at any measurement. In the $1 \mathrm{st}$ hour, preferences for saline were 89,81 and $74 \%$ for the 0,20 and $50 \mu \mathrm{g}$ doses, respectively.

The effect of naloxone on intake in rats given water and $1.7 \%$ saline were generally reversed compared to rats given $0.6 \%$ saline. Water intake was greater than $1.7 \%$ saline intake, and was reduced by naloxone. On the other hand, saline intake was unchanged or increased. The $50 \mu \mathrm{g}$ dose decreased water intake at 1 and $2 \mathrm{~h}$ and significantly increased 3-h NaCl intake. Intakes after the $20 \mu \mathrm{g}$ dose were in the same direction but were not statistically reliable (Dunnett's test, two-tailed). The dose factor was significant only at $1 \mathrm{~h}[F(2,18)=3.78, P<0.05]$. At 1,2 and $3 \mathrm{~h}$, there were significant fluid effects $[F(1,9)=211.03,199.74$ and $125.22]$ and significant dose $\times$ fluid interactions $[F(2,18)=$ $4.62,9.59$ and 5.22 , all $\left.P^{\prime} s<0.05\right]$. Saline preference was not significantly affected in the 1 st hour $(15,24$ and $17 \%$
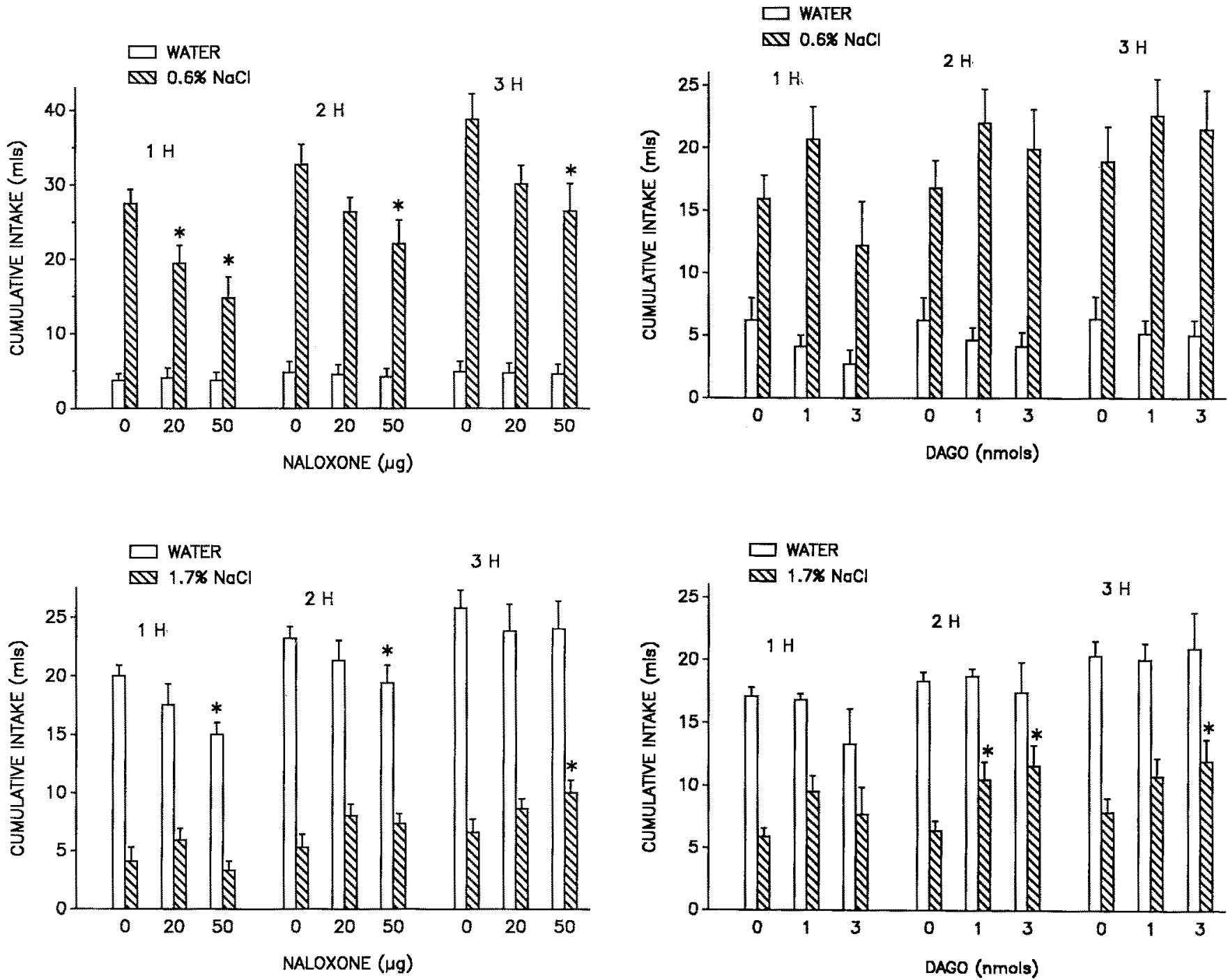

Fig. 1. Cumulative intake of water and saline solutions following ICV injections of naloxone (mean +SEM). All rats were tested during maintenance on a water deprivation schedule, and each rat was tested with all doses. Top: Rats were given access to both water and $0.6 \% \mathrm{NaCl}(n=11)$, Bottom: Rats were given access to both water and $1.7 \% \mathrm{NaCl}(n=10)$. Asterisks indicate significant differences from the corresponding $0 \mathrm{nmol}$ (water) condition $(P<$ 0.05, two-tailed Dunnett's test)

Fig. 2. Cumulative intake of water and saline solutions following ICV injections of the mu agonist DAGO (mean +SEM). All rats were tested during maintenance on a water deprivation schedule, and each rat was tested with all doses. Top: Rats were given access to both water and $0.6 \% \mathrm{NaCl}(n=11)$. Bottom: Rats were given access to both water and $1.7 \% \mathrm{NaCl}(n=8)$. Asterisks indicate significant increases above the corresponding $0 \mathrm{nmol}$ (saline) condition ( $P<0.05$, two-tailed Dunnett's test) 
for the 0,20 and $50 \mu \mathrm{g}$ doses, respectively). Based on 2and 3-h cumulative intakes, both doses of naloxone significantly increased $1.7 \%$ saline preference $(18,27$ and $27 \%$ for the 0,20 and $50 \mu \mathrm{g}$ doses at $2 \mathrm{~h}$ ).

In deprived rats given water and $0.6 \% \mathrm{NaCl}, \mathrm{DAGO}$ ( $3 \mathrm{nmol}$ ) tended to decrease intake in the 1 st hour; thereafter, both doses tended to decrease cumulative water intake and increase saline intake (Fig. 2). None of these effects, however, were statistically reliable (two-tailed Dunnett's test, all $P$ ' $>>0.05$ ). In a two-factor ANOVA, there was a significant fluid effect at 1,2 and $3 \mathrm{~h}[F(1,10)=24.18$, 33.93 and 29.29 , all $\left.P^{\prime} s<0.05\right]$. At $1 \mathrm{~h}$, there was also a significant dose effect $[F(2,20)=4.35]$, which is due primarily to the large difference between the 1 and 3 nmol treatment conditions. Mean preference for $0.6 \%$ saline was slightly increased by DAGO (at $2 \mathrm{~h}, 73,81$ and $82 \%$ for the 0,1 and 3 nmol treatments, respectively), but these increases were not significant.

In deprived rats given water and $1.7 \%$ saline, both doses of DAGO (1 and $3 \mathrm{nmol}$ ) increased 2-h cumulative saline intake; $3-\mathrm{h}$ intake was increased only in the 3 nmol condi-
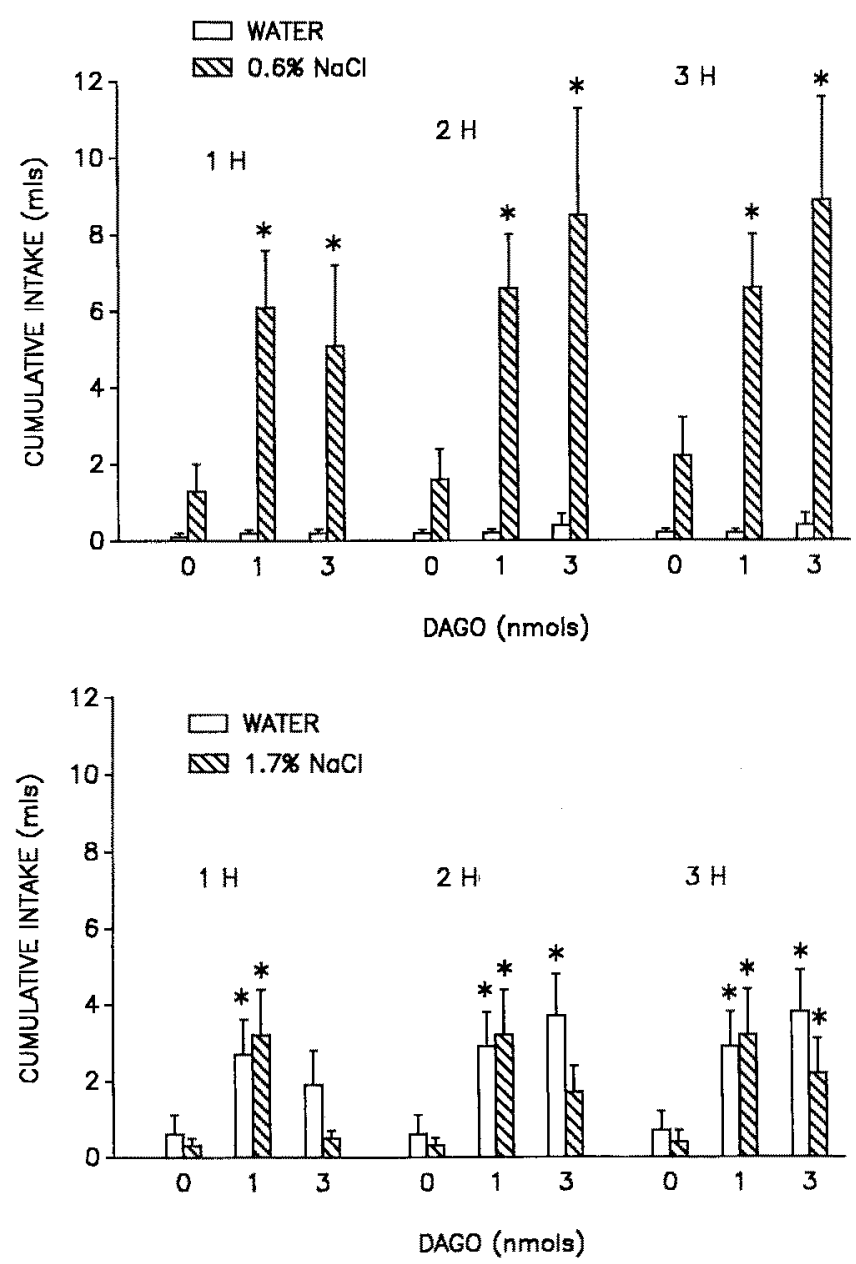

Fig. 3. Cumulative intake of water and saline solutions following ICV injections of the $\mathrm{mu}$ agonist DAGO (mean $+\mathrm{SEM}$ ). All rats were tested in the non-deprived condition, and each rat was tested with all doses. Top: Rats were given access to both water and $0.6 \% \mathrm{NaCl}(n=11)$. Bottom: Rats were given access to both water and $1.7 \% \mathrm{NaCl}(n=8)$. Asterisks indicate significant increases above the corresponding $0 \mathrm{nmol}$ (saline) condition $(P<0.05$, onetailed Dunnett's test) tion. Water intake was not significantly affected at any point. There was a significant fluid effect at 1,2 and $3 \mathrm{~h}$ $[F(1,7)=38.76,31.77$ and 31.33$]$ and a significant dose $\times$ fluid interaction at 1 and $2 \mathrm{~h}[F(2,14)=3.84$ and 5.45, all $P$ ' $S<0.05]$. Based on $1 \mathrm{~h}$ intakes, saline preference was increased by DAGO, but the increases were not significant. Based on 2-h cumulative intakes, both doses significantly increased saline preference $(25,35$ and $41 \%$ for the 0,1 and $3 \mathrm{nmol}$ doses, respectively). A similar pattern was observed when preferences were based on 3-h cumulative intakes.

In non-deprived rats trained to drink either $0.6 \%$ saline or water, DAGO (1 and $3 \mathrm{nmol}$ ) caused increases in cumulative saline intake measured at 1,2 and $3 \mathrm{~h}$ (Fig. 3 ). The mean intake of water in all three drug treatment conditions was negligible (less than $0.5 \mathrm{ml}$ ) and therefore was not analyzed. Intakes were also increased in rats receiving the $1.7 \%$ saline solution (Fig. 3). In the control condition (saline injection), mean intakes of both water and 1.7\% saline were less than $1.0 \mathrm{ml}$. A two-factor ANOVA (dose $\times$ fluid) indicated a significant effect of dose at 1,2 and $3 \mathrm{~h}[F(2,14)=$ 9.19, 12.41 and 13.37, all $\left.P^{\prime} s<0.05\right]$; the fluid effect (water versus saline) and the dose $x$ fluid interaction were not sig. nificant. Dunnett's tests indicated that the $1 \mathrm{nmol}$ dose significantly increased water and saline intake at 1,2 and $3 \mathrm{~h}$; the $3 \mathrm{nmol}$ dose increased cumulative water intake at $2 \mathrm{~h}$ and water and saline intake at $3 \mathrm{~h}$.

\section{Discussion}

A number of studies have shown that opioid agonists and antagonists cause increases and decreases, respectively, in the preference for or intake of sweet-tasting fluids (LeMagnen et al. 1980; Calcagnetti and Reid 1983; Cooper 1983; Siviy and Reid 1983; Czirr and Reid 1986; Lynch 1986). It has been suggested, therefore, that endogenous opioid peptides play a role in mediating the pleasureable or rewarding aspects of the tastes of these fluids (see Reid 1985; Cooper et al. 1988). There is evidence, however, that this postulated role for opioids may not be limited to sweet tastes. Cooper and Gilbert (1984) have shown that the antagonist naloxone causes a selective reduction in the intake of hypotonic saline solutions, while Bertino et al. (1988) found that morphine increased the intake of both isotonic and hypertonic saline solutions. The present results support and extend these findings by showing that similar results are obtained with central injections of naloxone and a selective mu agonist.

Non-deprived rats given placebo injections consumed negligible amounts of water and very little $0.6 \%$ saline. Central injections of the $\mathrm{mu}$ receptor agonist DAGO produced significant increases in saline intake, while water intake remained minimal. When non-deprived rats were given water and $1.7 \%$ saline, DAGO increased the intake of both fluids. In the non-deprived state, the taste of the salt solutions presumably provides the primary incentive to drink. Our finding that DAGO stimulated saline intake, then, is consistent with the hypothesis that opioids play a role in mediating the preference for palatable solutions. We have recently found that centrally administered DAGO produces a similar effect on the intake of a palatable saccharin solution (0.15\%) (Gosnell and Majchrzak 1989, in press).

In non-deprived rats given water and $1.7 \%$ saline, it is possible that the observed water intake following DAGO 
injections was secondary to intake of $1.7 \%$ saline, as it is well known that intubation of hypertonic saline elevates the intake of water (Stellar et al. 1954). As a test of whether DAGO would stimulate water intake when saline was not available, we performed a brief test utilizing rats from the non-deprived experiment. Test procedures were similar to those described above, except that only water was given, and rats were given injections of $\mathrm{NaCl}(n=3)$ or DAGO ( $3 \mathrm{nmol}, n=6$ ) in a single trial. Following DAGO injections, mean cumulative water intakes at 1,2 and $3 \mathrm{~h}$ were $0.7 \pm 0.3,1.4 \pm 0.4$ and $1.7 \pm 0.3 \mathrm{ml}$, respectively. These values were not significantly different from those of $\mathrm{NaCl}$ injected rats $(0.8 \pm 0.5 \mathrm{ml}$ at 1,2 and $3 \mathrm{~h})$. This lack of effect supports the view that the observed water intake in experiment 3 was secondary to the ingestion of hypertonic saline. It is likely that with a more frequent measuring of intake, an increase in saline intake would be found to precede increases in water intake.

In water-deprived rats, the initial effects of DAGO on intake were dose dependent: the low dose $(1 \mathrm{nmol})$ tended to increase saline intake, while the $3 \mathrm{nmol}$ dose tended to decrease intake. It is probable that the decrease observed with the $3 \mathrm{nmol}$ dose is due to motor impairment, as this dose initially produces catalepsy. Beyond the 1 st hour, both doses tended to increase saline intake. Water intake was slightly reduced by both doses, such that the percentage of total fluid taken as saline tended to increase. When the choice was between water and $1.7 \%$ saline, DAGO increased intake of $1.7 \%$ saline and slightly reduced or had no effect on water intake. These results resemble those of Bertino et al. (1988), who found that systemic injections of morphine increased intakes of 0.9 and $1.5 \%$ saline.

Centrally administered naloxone $(50 \mu \mathrm{g})$ reduced preference for $0.6 \%$ saline from $89 \%$ (control condition) to $74 \%$ (based on 1-h intakes). Cooper and Gilbert (1984) reported a similar reduction following systemic injection of naloxone $(10 \mathrm{mg} / \mathrm{kg})$. As with our results, the reductions in preference were not statistically significant. However, in both cases, naloxone significantly reduced intake of $0.6 \%$ saline; water intake was low and was unaffected by naloxone. We observed an opposite pattern when rats were given water and $1.7 \%$ saline. Naloxone significantly reduced water intake and caused a slight, delayed increase in $1.7 \%$ saline intake. Thus, regardless of which saline concentration was paired with water, the primary effect of naloxone was to reduce intake of the fluid consumed in the largest quantity.

In contrast to the present results. Cooper and Gilbert (1984) found that systemically administered naloxone caused equivalent reductions of both water and $1.7 \%$ saline intake, such that preference was unchanged. Aside from the differences in route of naloxone administration, one possible explanation for the difference between their results and ours concerns baseline preference for $1.7 \%$ saline. With our procedures, preference for $1.7 \%$ saline was $15-20 \%$ in the naloxone trials and $25-27 \%$ in the DAGO trials. Cooper and Gilbert (1984) reported a preference of $43.9 \%$, a value not significantly less than $50 \%$. This difference in preference may be related to the duration of intake tests. We measured hourly intake for $3 \mathrm{~h}$, whereas Cooper and Gilbert allowed a choice of fluids for only $15 \mathrm{~min}$.

It should be noted that $1.7 \%$ saline is not necessarily aversive to rats, even though hypertonic saline solutions are generally placed on the descending limb of a preferenceaversion curve (Weiner and Stellar 1951; Stellar et al. 1953;
Khavari 1970). Stellar et al. (1953) have shown that the descending limb of this curve for salt solutions is due largely to post-ingestive osmotic effects. When using a measure of taste reactivity which is independent of ingestion, Grill and Norgren (1978) found that sodium chloride as strong as $1.3 \mathrm{M}(7.6 \%)$ elicited no rejection responses. Schwartz and Grill (1984) reported that hypertonic saline solutions elicit rejection responses only after prolonged oral infusions. They make a distinction between aversion and avoidance, and report that with short ( $1 \mathrm{~min}$ ) oral infusions, hypertonic saline solutions elicit purely ingestive responses. Thus, while rats avoid hypertonic solutions, there is no unequivocal evidence that they are unpalatable. However, the palatability-enhancing effect of DAGO may be confounded by the apparently aversive post-ingestive consequences of hypertonic saline.

Although both naloxone and DAGO significantly increased the percentage of total intake consumed as $1.7 \%$ saline, their effects on the intakes of individual fluids were different. Following treatment with DAGO, 2-h cumulative saline intake was increased by 4.1 and $5.2 \mathrm{ml}$ by the 1 and $3 \mathrm{nmol}$ doses, respectively, while mean water intakes changed by less than $1 \mathrm{ml}$ for both doses. In naloxonetreated animals, there was a decrease in water intake and an increase in saline intake. The 20 and $50 \mu \mathrm{g}$ doses decreased 2-h cumulative water intake by 1.9 and $3.8 \mathrm{ml}$, repectively, and increased saline intake by 3.7 and $2.0 \mathrm{ml}$. That a significant increase in saline intake was not observed until the final measurement ( $3.25 \mathrm{~h}$ post-injection) suggests that this increase may not be a direct result of opioid blockade.

Relative to the magnitude of their respective baselines, DAGO- and naloxone-induced changes of intake in deprived rats were generally small. It is possible that the deprivation schedule was sufficiently severe to provoke near maximal drinking regardless of pharmacological manipulations. An additional factor which may have obscured or diminished the effects of DAGO and naloxone in the deprived condition is the greater variability in intake observed in deprived versus non-deprived rats. Young and Falk (1956) have reported that compared to non-thirsty rats, thirsty rats show more individual differences in saline preference, more indiscriminate behavior, and more mutations of preference.

The intake and excretion of both water and sodium are prominent factors in the regulation of water balance. It is conceivable, then, that the observed behavioral responses to the administration of naloxone and DAGO could represent compensatory behaviors for DAGO- or naloxone-induced changes in the excretion of water and/or sodium. This appears unlikely, however, as naloxone has been reported to have no effect on urine flow or sodium or potassium excretion (Danesh and Walker 1988). Chronic treatment with the antagonist naltrexone was reported to reduce urine flow and sodium, potassium and total osmolar excretions, but these changes were attributed to a reduction in food and water intake, since water and electrolyte balance were unchanged (Lang et al. 1982). Central administration of morphine, an agonist primarily at mu receptors, decreased urine flow and sodium excretion (Danesh and Walker 1988). One would expect, therefore, that a compensatory behavioral response to these effects of a mu agonist would be a decrease in saline intake, rather than the observed increases. Thus, it is doubtful that changes in water 
balance and/or electrolyte excretion underlie the effects reported here.

Several lines of evidence suggest that central rather than peripheral opioid peptides and receptors are involved in the regulation of ingestion (see Sanger 1983; Gosnell 1986; Cooper et al. 1988). The effects of DAGO in the present studies support a role for central opioid peptides and receptors in the control of saline preference as well. In the experiments with naloxone, however, a peripheral site of action cannot be ruled out, as the doses injected are near the low end of the range of doses which have been reported to affect fluid intake or preference when injected systemically ( 20 and $50 \mu \mathrm{g}$ equal approximately 0.07 and $0.17 \mathrm{mg} / \mathrm{kg}$ for a $300 \mathrm{~g}$ rat) (Cooper 1983; Cooper and Turkish 1983; Siviy and Reid 1983; Cooper and Gilbert 1984; Lynch 1986). Additional studies with quaternary naloxone would be useful in confirming a central site of action for naloxone.

In summary, central injections of the mu opioid agonist DAGO caused selective increases in the intake of $0.6 \%$ saline, while injections of naloxone caused selective decreases in intake of saline. When water and $1.7 \%$ saline were available, DAGO selectively increased saline intake in deprived rats and increased consumption of both fluids in non-deprived rats. Naloxone significantly decreased water intake and caused a delayed increase in $1.7 \%$ saline intake. Post-ingestive osmotic effects are a potential confound in interpreting the results of experiments utilizing hypertonic saline. Generally, these results support the suggestion that endogenous opioid peptides play a role in mediating the preference for salt solutions.

Acknowledgements. This research was supported by NIDA grant DA05471.

\section{References}

Bertino M, Abelson ML, Marglin SH, Neuman R, Burkhardt CA, Reid LD (1988) A small dose of morphine increases intake of and preference for isotonic saline among rats. Pharmacol Biochem Behav 29:617-623

Calcagnetti DJ, Reid LD (1983) Morphine and acceptability of putative reinforcers. Pharmacol Biochem Behav 18:567-569

Cooper SJ (1983) Effects of opiate agonists and antagonists on fluid intake and saccharin choice in the rat. Neuropharmacology $22: 323-328$

Cooper SJ, Gilbert DB (1984) Naloxone suppresses fluid consumption in tests of choice between sodium chloride solutions and water in male and female water-deprived rats. Psychopharmacology $84: 362-367$

Cooper SJ, Turkish S (1983) Effects of naloxone and its quaternary analogue on fluid consumption in water-deprived rats. Neuropharmacology 22:797-800

Cooper SJ, Jackson A, Kirkham TC, Turkish S (1988) Endorphins, opiates and food intake. In: Rodgers RJ, Cooper SJ (eds) Endorphins, opiates and behavioral processes. John Wiley and Sons, New York, pp 143-186

Czirr SA, Reid LD (1986) Demonstrating morphine's potentiating effects on sucrose-intake. Brain Res Bull 17:639-642

Danesh S, Walker LA (1988) Effects of central administration of morphine on renal function in conscious rats. J Pharmacol Exp Ther 244:640-645

Gosnell BA (1987) Central structures involved in opioid-induced feeding. Fed Proc 46:163-167

Gosnell BA, Majchrzak MJ (1989) Centrally administered opioid peptides stimulate saccharin intake in non-deprived rats. Pharmacol Biochem Behav (in press)

Gosnell BA, Levine AS, Morley JE (1986) The stimulation of food intake by selective agonists of mu, kappa and delta opioid receptors. Life Sci 38:1081-1088

Gosnell BA, Grace M, Levine AS (1987) Effects of $\beta$-chlornaltrexamine on food intake, body weight and opioid-induced feeding. Life Sci 40:1459-1467

Grill HJ, Norgren R (1978) The taste reactivity test. I. Mimetic responses to gustatory stimuli in neurologically normal rats. Brain Res 143:263-279

Handa BK, Lane AC, Lord JAH, Morgan BA, Rance MJ, Smith CFC (1981) Analogues of $\beta-\mathrm{LPH}_{61-64}$ possessing selective agonist activity at $\mu$-opiate receptors. Eur $\mathbf{J}$ Pharmacol 70:531-540

Khavari K (1970) Some parameters of sucrose and saline ingestion. Physiol Behav 5:663-666

Kuta CC, Bryant HU, Zabik JE, Yim GKW (1984) Stress, endogenous opioids and salt intake. Appetite 5:53-60

Lang IL, Strahlendorf JC, Strahlendorf HK, Lutherer LO, Barnes CD (1982) The effects of chronic administration of naltrexone on appetite and water exchange in rats. Pharmacol Biochem Behav 16:909-913

Le Magnen J, Marfaing-Jallat P, Miceli D, Devos M (1980) Pain modulating and reward systems: a single brain mechanism? Pharmacol Biochem Behav 12:729-733

Levine AS, Murray SS, Kneip J, Grace M, Morley JE (1982) Flavor enhances the antidipsogenic effect of naloxone. Physiol Behav $28: 23-25$

Levine AS, Morley JE, Gosnell BA, Billington CJ, Bartness TJ (1985) Opioids and consummatory behavior. Brain Res Bull $14: 663-672$

Lynch WC (1986) Opiate blockade inhibits saccharin intake and blocks normal preference acquisition. Pharmacol Biochem Behav 24:833-836

Reid LD (1985) Endogenous opioid peptides and regulation of drinking and feeding. Am J Clin Nutr 42:1099-1132

Sanger DJ (1983) Opiates and ingestive behavior. In: Cooper SJ (ed) Theory in Psychopharmacology, Vol. 2. Academic Press, New York, pp 75-113

Sanger DJ, McCarthy PS (1980) Differential effects of morphine on food and water intake in food deprived and freely feeding rats. Psychopharmacology 72:103-106

Schwartz GJ, Grill HJ (1984) Relationships between taste reactivity and intake in the neurologically intact rat. Chem Senses $9: 249-272$

Siviy SM, Reid LD (1983) Endorphinergic modulation of acceptability of putative reinforcers. Appetite 4:249-257

Stellar E, Hyman R, Samet S (1954) Gastric factors controlling water- and salt-solution-drinking. J Comp Physiol Psychol 47:220-226

Turkish S, Cooper SJ (1984) Effects of a kappa receptor agonist, ethylketocyclazocine, on water consumption in water-deprived and nondeprived rats in diurnal and nocturnal tests. Pharmacol Biochem Behav 21:47-51

Ukai M, Nakayama S, Kameyama T (1988) The opioid antagonist, MR2266, specifically decreases saline intake in the mouse. Neuropharmacology 27:1027-1031

Weiner IH, Stellar E (1951) Salt preference of the rat determined by a single-stimulus method. J Comp Physiol Psychol 44:394 401

Wild KD, Marglin SH, Reid LD (1988) Small doses of morphine enhance voluntary intake of a solution of only ethanol and water. Bull Psychon Soc 26:129-131

Young PT, Falk JL (1956) The relative acceptability of sodium chloride solutions as a function of concentration and water need. J Comp Physiol"Psychol 49:569-575

Received June 5, 1989 / Final version July 24, 1989 